This study investigated the effects of reading extremely violent comic books (EVCB) versus nonviolent comic books (NVCB) on the interpretation of overt and relational ambiguous provocation situations. Two hundred forty-nine introductory psychology students read either EVCB or $N V C B$. After reading the comic books, participants read hypothetical stories in which overt or relational aggression occurred but the intent of the provocateur was ambiguous. After each story, participants were asked a series of questions about the provocateur's intent, potential retaliation toward the provocateur, and the provocateur's emotional state. Trait hostility was significantly related to hostile responding. Regardless of the type of aggression, participants reading EVCB responded more negatively than participants reading $N V C B$ did. Males responded more negatively to the overt scenarios, whereas females responded more negatively to the relational scenarios. Results indicate that interpretation of ambiguous material appears to be affected by a number of variables, including gender, trait hostility, and violent media.

\title{
The Effects of Extremely Violent Comic Books on Social Information Processing
}

\author{
STEVEN J. KIRSH \\ PAUL V. OLCZAK \\ State University of New York, Geneseo
}

Although the impact of media violence has been underreported by news services (Bushman \& Anderson, 2001), research has consistently found that exposure to violent media appears to increase aggressive behavior, thoughts, and feelings in children, adolescents, and young adults (Anderson, 1997). The vast majority of this research has focused on portrayals of violence in television, movies, and, more recently, video games. However, an understudied source of violent content to which children and adolescents are exposed comes from comic books. Although the effects of violent comic books on children came under scrutiny in the 1950s, today, the deleterious effects of video games are receiving a great deal of interest from both researchers and politicians. However, scores of comic books currently being sold are also laden with extreme depictions of violence. For instance, comic books such as

\footnotetext{
Authors' Note: Address correspondence concerning this article to Steven Kirsh, Department of Psychology, State University of New York, Geneseo, Geneseo, NY 14454; phone: (585) 2455215; fax: (585) 245-5235; e-mail: kirsh@geneseo.edu.

JOURNAL OF INTERPERSONAL VIOLENCE, Vol. 17 No. 11, November 2002 1160-1178 DOI: $10.1177 / 088626002237400$

(C) 2002 Sage Publications

1160
} 
Homicide, Spawn, and Evil Ernie frequently depict brutal acts of aggression. These acts include graphic illustrations of bloody decapitations, vivid eviscerations, and sinewy amputations. The weapons used to commit these heinous acts range from machine guns to machetes and an array of body parts including fingernails, toenails, and teeth.

Comic books, unlike video games, do not provide a continuous story in which all of the action relevant to the story line is exhibited. In comic books, the story line is told in partially connected frames. Thus, to create a continuous story line, the reader provides continuity between frames. For instance, if one frame depicts a muscular hero swinging an ax toward his crouching enemy, the next frame would show the victim's head severed from his body, spurting blood. Thus, it is up to the reader to visualize that actual decapitation. This type of disconnected presentation of information forces the reader to engage his or her imagination and become an active participant in the violence-laden story line (McCloud, 1993). Furthermore, another factor contributing to story line engagement is that comic books are read at a comfortable, self-guided pace (Potenza, Verhoeff, \& Weiss, 1996).

There are several advantages of using comic books to assess the impact of media violence. In contrast to playing a video game, reading a comic book is devoid of arousal associated with motor movements. Although much of the arousal associated with violent video games will come from the violent components of video game play, the arousal associated with motor movements becomes an unwarranted artifact that has the potential to confound data. In contrast, the physiological arousal experienced by a comic book reader will most likely be due to the images in the comic books alone or an interaction of the images with the individual's personality characteristics. Furthermore, comic books may be less likely than video games to cause the participants to feel frustrated. Assessments of video games typically require participants to play a video game for 10 to 20 minutes and then stop, regardless of where they are in the game. It is possible that participants feel frustrated from having to stop playing the game prematurely. In contrast, when using comic books as the medium of media violence, an individual typically gets to read an entire comic book. In addition, the outcome (e.g., winning or losing) the video game being played can cause frustration. For instance, Kirsh (1998) found that children that tied a basketball video game gave more hostile responses to ambiguous provocation questions than children either winning or losing a basketball video game. Furthermore, it is difficult to find a sample of participants who do not play video games regularly. Estimates suggest that $84 \%$ of adolescents play video games on a frequent basis (Funk, 1993; Walsh 1999). In contrast, because comic books are not nearly as popular as video games, the impact of previous exposure to the experimental stimuli is mitigated. 
Thus, the outcomes associated with reading violent comic books may be less likely than video games to be influenced by confounds such as motor arousal, frustration, and previous exposure to the stimuli.

Given the convergent validity of the effects of different forms of violent media on aggression (Bushman \& Anderson, 2001), the findings associated with comic book violence should be similar to those of other forms of violent media. Recent research suggests this is the case. For instance, studies involving comic books (Kirsh \& Olczak, 2000) and video games (Lynch, Gentile, Olson, \& van Brederode, 2001) have demonstrated links between media violence and inferring hostile intent to the actions of another, even though the intent of that individual is unclear (Dill, Anderson, Anderson, \& Deuser, 1997; Dodge, 1980). Dodge (1986) contends that individuals act aggressively and perceive hostility (when none is present) due to biases in social information processing (SIP). According to Dodge's SIP model, when frustrated or hurt in social situations (e.g., being pushed into a puddle), a series of social cognitive steps are enacted. Dodge's SIP steps include encoding of social cues (e.g., look at smiling provocateur), interpretation of social cues (e.g., provocateur has a malicious smile; harm was done on purpose), problem-solving strategies (e.g., aggressive retaliation usually works), and the enactment of behavior (e.g., hit the child). In support of this theory, research has shown that the SIP of aggressive children is replete with aggression-laden (i.e., aggressively biased) perceptions, interpretations, and decision making (Dodge \& Crick, 1990).

Despite the high level of aggression in comic books, little recent research has assessed the impact of violence in comics on aggressive behavior and thoughts (Potenza et al., 1996). The research that has been conducted, however, suggests that exposure to violent themes in comic books may aggressively bias an individuals' SIP. For instance, Kirsh and Olczak (2000) biased the SIP of adult men toward aggression (e.g., increased levels of hostile attributions about intent), but not women, by having them read violent comic books. Although Kirsh and Olczak's initial research on overt aggression suggested that violent comic books may have a bigger negative impact on the SIP of men than women, more recent research suggests that type of aggressive conflict assessed may also be important. Specifically, Kirsh and Olczak (2002) found that both men and women demonstrate increased aggressive responding when the dependent variable involves judgments of relational aggression (however, the level of biased responding did not differ between men and women). Relational aggression involves social exclusion (e.g., not inviting someone to a party) or social manipulation (e.g., spreading rumors, threatening not to be a friend) to control another's behavior (Crick, 1995). Kirsh and Olczak's (2002) findings are consistent with previous research 
suggesting that the presence or absence of aggression-related gender differences may be related to the type of aggressive conflict under study (e.g., relational or overt aggression; see Bartholow \& Anderson, in press). However, the number of men in the sample used in Kirsh and Olczak (2002) was relatively small, and thus the failure to find gender differences may have been due to a lack of statistical power.

Overt and relational forms of aggression represent different types of aggressive conflicts (Crick \& Grotpeter, 1995) and thus have potentially different antecedents and consequences. For instance, whereas boys are more likely than girls to engage in acts of overt aggression (Parke \& Slaby, 1983), relational aggression appears to be more characteristic of girls than boys (Crick \& Grotpeter, 1995). These findings are consistent with research indicating that males are more likely than females to engage in direct aggression (e.g., physical violence), whereas females are more likely than males to engage in indirect aggression (e.g., verbal aggression; see Bartholow \& Anderson, in press). Thus, it is hypothesized that similar patterns of responding will be shown for aggression-related SIP in the current study, with males providing more aggressive responses to overt provocation scenarios and females manifesting more aggression for relational provocation scenarios.

To test the proposition that reading extremely violent comic books (EVCB) influences the SIP of overt and relational aggression, participants will read either EVCB or nonviolent comic books (NVCB). It should be noted that the present experimental stimuli depict acts of overt aggression but do not depict acts of relational aggression. Why then, should we expect to see violent comic books that do not contain relational aggression bias SIP involving relational aggression? Bushman (1998) contended that exposure to violent media primes an individual's aggressive network. As a result of this priming, associations among aggressive thoughts, memories, and emotions are formed. In addition, an accessible network is believed to aid in the processing and interpretation of social information (Bushman, 1998). Factors that make an aggressive network accessible include frequent use (e.g., habitual aggressive behavior) or priming (i.e., exposure to aggressive stimuli). Furthermore, the type of the priming involved (e.g., exposure to hitting) does not have to be related to the observed aggressive behavior (e.g., yelling) or thoughts associated with an accessible aggressive network (Bushman, 1998).

For the present study, exposure to EVCB should prime participants' aggressive network, potentially influencing participants' responses to both the overt and relational provocation scenarios. Thus, it is hypothesized that individuals exposed to EVCB will show evidence of a biased SIP and respond more aggressively than adults exposed to NVCB do. Furthermore, we expect that the impact of violence in comic books will be manifested differently for 
males and females. Specifically, we expect that males exposed to EVCB will provide more aggressive responses to overt provocation scenarios and females exposed to EVCB will manifest more aggression for relational provocation scenarios.

Repeated activation of an aggressive network should make it chronically accessible (Bushman, 1998). Thus, individuals high in trait hostility should process social information differently than should individuals low in trait hostility. Recent research demonstrating a positive correlation between trait hostility and increases in hostile attributions supports this contention (Epps \& Kendall, 1995). Similarly, previous research using violent comic books has found a significant and positive relationship between trait hostility and aggressively biased SIP involving overt ambiguous provocation scenarios (Kirsh \& Olczak, 2000). Thus, based on previous research linking trait hostility to hostile responding, we expect to find that as trait hostility increases, participants will provide more aggressive responding. Research on television has demonstrated that preexisting anger appears to increase the negative influence of violent television (Dubow \& Miller, 1996). Additional research has shown that individuals high in trait hostility are affected more by violent video games than are individuals low in trait hostility (Anderson \& Dill, 2000). Thus, we expect to find that participants high in trait hostility will provide the most negative responses after exposure to violent comic books. Furthermore, we expect these effects to be greatest for males in response to the scenarios involving overt aggression and for females in response to the scenarios involving relational aggression.

In summary, the primary purpose of the present research is to investigate the influence of comic books on SIP related to both overt and relational aggression. We expect EVCB to bias SIP toward aggressive responding and that these effects should be greatest for individuals high in trait hostility. Furthermore, we expect to find that males and females will respond differently depending on the type of aggression depicted, with males providing the most negative responses to overtly aggressive scenarios and females manifesting the most negative responses to relationally aggressive scenarios.

\section{METHOD}

\section{Participants}

The participants were 249 introductory psychology students $(67 \%$ female) at a mid-sized college in western New York State. The distribution of 
males and females in this study approximated the gender distribution at the college.

\section{Procedure}

At the beginning of the semester, participants filled out the Buss-Durkee Hostility Inventory (BDHI) (Buss \& Durkee, 1957) to assess their trait level of hostility. Approximately 6 to 10 weeks later, these participants were recruited to participate in the comic book study. Research assistants, blind to the participants' trait hostility scores, randomly assigned participants to one of two conditions: extremely violent and nonviolent. Participants in the extremely violent condition read comic books with a high degree of violence and aggressive themes. Participants in the nonviolent condition read a relatively nonviolent comic book.

To help reduce the demand characteristics of the study (i.e., linking comic books to responses for the ambiguous provocation situations), participants were told that the researchers were developing measures for two separate studies on children and that they needed their input to help develop appropriate measures. Specifically, participants were told that one of the studies deals with children's perceptions of comic books and that the other study assesses children's perceptions of things that happen to them at home and at school. First, participants read their assigned comic book and completed the comic book rating task. Then, as a separate assessment, participants read and answered questions about a series of overt and relational provocation stories. For this task, participants were asked to respond to the questions as they thought a 10-year-old would respond. The ambiguous provocation stories task is a type of projective test. Thus, participants' responses should reflect their current state of mind, with regard to hostile/nonhostile perceptions. Whereas some participants will respond negatively, others will respond neutrally or positively. The positive/negative perceptions associated with participants' "childlike" responses are in fact projections of the participants' current cognitive state. At the same time, this line of questioning should maintain the pretense that the researchers were developing experimental measures for children. Finally, participants were asked a series of questions about their own experience with comic books using a comic book history form.

\section{Materials}

Comic books. The EVCB shown to participants were Cremator, Curse of the Spawn, Dark Realm, Evil Ernie, Homicide, Purgatory, and Undertaker. 
Approximately $80 \%$ of the panels in the EVCB contain aggressive acts and/ or themes: Examples include amputations, bloodletting, fighting, gore, killing, threatening words, property destruction, and forcible restraint. The NVCB shown to participants were Archie, Cherry Blossom, Dexter's Laboratory, Pocohontas, Rugrats, and Sabrina. Less than $10 \%$ of the panels in the NVCB contain aggressive acts and/or themes: Examples include pushing, name calling, and tripping. Both the EVCB and NVCB were examined by two independent coders for instances of relational aggression; none were found. There were no disagreements between coders.

To help equate the two experimental conditions on reading, related boredom, and fatigue, participants in the extremely violent condition read two full EVCB whereas participants in the nonviolent condition read one or two NVCB depending on which comic books were assigned. Both conditions involved approximately 20 minutes of reading. Regardless of comic book condition, all participants read completed story lines.

Comic book history form. Participants were asked to provide a list of comic books they have read in the past 6 months and how often they read comic books.

Comic book rating form. To reduce demand characteristics and maintain the ruse that we needed comic book ratings for a future study, we asked participants to rate the violence ("aggression"), humor ("humor"), interest level ("interest"), and overall likeability ("like") of their assigned comic book. All questions involved 7-point Likert-type scales.

Predispositional anger. Participants' propensity to respond to a variety of situations with anger was assessed using the BDHI. The BDHI consists of 75 true/false questions made up of seven subscales and a total hostility score. Studies using the total score on the BDHI as a global measure of hostility have found that high scorers retaliated sooner and delivered significantly more and stronger shocks to another person than low scorers did in an experimental aggression situation (Knott, 1970) and that they perceived significantly more aggression than low scorers did in a binocular rivalry situation (Petzel \& Michaels, 1973). Median splits were used to create high hostility and low hostility variables.

Ambiguous provocation stories task. For this assessment, participants read six hypothetical stories in which an aggressive event occurs to a child but the intent of the provocateur is unclear (see the appendix). Three of the scenarios involve potential acts of overt aggression (e.g., getting hit in the back 
with a ball), and three of the scenarios involve potential acts of relational aggression (e.g., not being invited to a birthday party). For each scenario, the gender of both the provocateur and of the child protagonist were not stated. The overt and relational provocation stories were adapted from a program of research conducted by Dodge (1980) and Crick (1995). The order of presentation for the stories was counterbalanced, with the limitation that no more than two like stories (e.g., relational) be presented in a row.

After each story, participants were asked six questions: two questions about the provocateur's intent (e.g., "Why did the kid ...?" "Do you think the kid was trying to be mean or not trying to be mean?"), two questions about potential retaliation and punishment toward the provocateur (e.g., "What would you do next after ...?" "After this happened, would you try to get back at the kid a lot, a little, or not at all?"), and two questions about emotional state (e.g., "How do you think the other kid feels about you right now?" "How would you feel after...??'). Responses were written down by participants and then coded in terms of amount of negative and aggressive content. Specifically, responses that indicated a high degree aggression and negative content (e.g., "I'd hit them"; "I'd make them suffer") were coded as a 2. Responses indicating a moderate amount of negative content or aggression (e.g., "They didn't like me"; "I'd spread a rumor about them") were coded as a 1. Neutral or positive responses (e.g., "They didn't know I sat down") were coded as a 0 . One coder, blind to experimental condition, coded the transcripts. A second coder, also blind, coded a randomly selected $25 \%$ of the transcripts. Interrater reliability (Cohen's kappa) was .91.

Data reduction. According to Dodge, Pettit, McClaskey, and Brown (1986), assessing the relationship between aggression and a combination of several SIP steps has more power than does assessing the relationship between aggression and individual SIP steps. As such, the data were reduced to reflect different conflict types (i.e., overt and relational aggression). Initial composite variables were formed by summing responses to like questions for like scenarios. Specifically, for each story type, (i.e., overt or relational) the two intent-related questions were combined to form an intent variable, the two punishment-related questions were combined to form a retaliation variable, and the two emotion-related questions were combined to form an emotion variable. These six variables were then entered in a factor analysis. The principle components analysis using varimax rotation with Kaiser normalization produced a two-factor solution accounting for $75 \%$ of the variance. Factor I consisted of overt intent, overt retaliation, and overt emotion, with factor loadings of $.89, .84$, and .85 , respectively. Factor II consisted of relational intent, relational retaliation, and relational emotion, with factor load- 
ings of $.83, .78$, and .80 , respectively. The cross-factor loadings for each variable ranged from .10 to .30 . Thus, based on the results from the factor analysis, two summated scales were formed: Overt Aggression (consisting of variables from Factor I) and Relational Aggression (consisting of variables from Factor II).

\section{RESULTS}

\section{Preliminary Analyses}

Comic book history. Few participants in this study had recently read a comic book. In fact, only $6 \%$ had read a comic book (violent or nonviolent) in the past 6 months. Thus, prior experience reading comic books does not appear to be a factor in this study.

Comic book ratings. To assess the relations among the comic book ratings, a series of Pearson correlation coefficients was computed. Significant positive correlations occurred between humor and interest $(r=.55, p<.001)$, interest and like $(r=.73, p<.001)$, and like and humor $(r=.73, p<.001)$. Significant negative correlations were evident between aggression and humor $(r=-.51, p<.001)$ and aggression and like $(r=-.42, p<.001)$. The negative correlation between interest and aggression approached significance $(r=$ $-.12, p<.06)$.

To verify that the comic books were categorized correctly, a 2 (comic book) $\times 2$ (gender) analysis of covariance (ANCOVA) was conducted for perceived aggression, with trait hostility as the covariate. Results indicated a significant main effect for comic book, $F(1,244)=1114, p<.0001$, with EVCB being rated as significantly more violent than NVCB. The main effect for gender, $F(1,244)=0.03, p<.86$, and the Comic Book $\times$ Gender, $F(1,244)=$ $0.19, p<.66$, interaction effect were both nonsignificant.

To test for differences in participants' perceptions of the comic books, a series of ANOVAs was conducted. For like, there was a significant main effect for comic book, $F(1,244)=44.5, p<.001$, and gender $F(1,244)=10.3$, $p<.001$. Participants liked NVCB significantly more than EVCB, and males liked the comic books more than females did. For humor, there was a significant main effect for comic book, $F(1,244)=75.8, p<.001$, in which NVCB were rated as significantly more humorous than EVCB were. However, the Comic Book $\times$ Gender interaction effect was significant for like, $F(1,244)=$ $45.2, p<.001$; humor, $F(1,244)=6.5, p<.01$; and interest, $F(1,244)=27.7$, $p<.001$. For like, follow-up pair-wise comparisons indicated that whereas 
TABLE 1: Estimated Means and Standard Errors for Comic Book Ratings

\begin{tabular}{|c|c|c|c|c|}
\hline & \multicolumn{4}{|c|}{ Comic Book Type } \\
\hline & \multicolumn{2}{|c|}{$\begin{array}{l}\text { Nonviolent } \\
\text { Comic Books }\end{array}$} & \multicolumn{2}{|c|}{$\begin{array}{c}\text { Extremely Violent } \\
\text { Comic Books }\end{array}$} \\
\hline & $\mathrm{M}$ & SE & M & SE \\
\hline \multicolumn{5}{|c|}{ How aggressive did you find your comic book? } \\
\hline Female & 2.1 & 0.11 & 6.6 & 0.11 \\
\hline Male & 2.2 & 0.15 & 6.5 & 0.11 \\
\hline \multicolumn{5}{|c|}{ How much did you like your comic book? } \\
\hline Female & 4.2 & 0.14 & 1.9 & 0.14 \\
\hline Male & 3.6 & 0.20 & 3.6 & 0.21 \\
\hline \multicolumn{5}{|c|}{ How interesting did you find your comic book? } \\
\hline Female & 4.2 & 0.16 & 3.0 & 0.15 \\
\hline Male & 3.3 & 0.21 & 4.1 & 0.15 \\
\hline \multicolumn{5}{|c|}{ How humorous did you find your comic book? } \\
\hline Female & 3.6 & 0.14 & 1.7 & 0.14 \\
\hline Male & 3.1 & 0.19 & 2.0 & 0.20 \\
\hline
\end{tabular}

females liked NVCB more so than did males $(p<.01)$, males liked EVCB more so than did females $(p<.001)$. For humor, pair-wise comparisons suggested that females found NVCB more humorous than did males $(p<.03)$. However, no gender differences were evident for humor for the EVCB condition. For interest, pair-wise comparisons indicated that females were more interested in NVCB than were males $(p<.001)$. Conversely, males were more interested in EVCB than were females $(p<.001)$. Given that participants' perceptions of the comic books may influence their responses to the ambiguous stories, like, humor, and interest were entered as covariates in subsequent analyses. Table 1 presents means and standard errors for the comic book ratings.

\section{Main Analyses}

To test the contention that EVCB influence the processing of social information, a 2 (comic book) $\times 2$ (gender) $\times 2$ (trait hostility) multivariate ANCOVA was conducted, with like, humor, and interest as the covariates. Results indicated significant multivariate main effects for comic book, $F(2$, $237)=9.76, p<.001$; gender, $F(2,237)=27.01, p<.001$; and trait hostility, $F(2,237)=3.07, p<.05$. The multivariate Comic Book $\times$ Gender interaction effect approached significance, $F(2,237)=2.35, p<.10$. The Comic Book $\times$ Trait Hostility, Gender $\times$ Trait Hostility, and Comic Book $\times$ Gender $\times$ Trait 
Hostility multivariate interaction effects were all nonsignificant, $F(2,237)=$ $1.57, p<.30 ; F(2,237)=2.19, p<.11$, and $F(2,237)=1.31, p<.27$, respectively. To assess the influence of the aggressive characteristics of the comic books on SIP, the above multivariate analyses were repeated with the addition of aggression to the list of covariates. Although the multivariate main effects for gender, $F(2,236)=26.93, p<.001$, and trait hostility, $F(2,236)=2.96 . p<$ .05 , remained significant, the multivariate main effect for comic book, $F(2$, $236)=0.18, p<.84$, was no longer significant. Thus, it appears that it is the violence depicted in the comic books that is primarily responsible for the comic book effects.

Follow-up univariate analyses of covariance were then conducted to investigate the significant multivariate effects and the a priori interaction effects, with like, interest, and humor as the covariates. For overt aggression, the univariate main effects for comic book, $F(1,238)=18.78, p<.001$; gender, $F(1,238)=22.83, p<.001$; and trait hostility, $F(1,238)=6.16, p<.015$, were significant. Results indicated that participants reading EVCB responded more aggressively than did participants reading NVCB. In addition, males responded more negatively than females did, and individuals high in trait hostility provided more aggressive responses than individuals low in trait hostility did. The Comic Book $\times$ Trait Hostility, Gender $\times$ Trait Hostility, and Comic Book $\times$ Gender $\times$ Trait Hostility interaction effects were all nonsignificant, $F(1,238)=2.27, p<.27 ; F(1,238)=0.64, p<.43$; and $F(1$, $238)=1.00, p<.32$, respectively.

For relational aggression, the univariate main effects for comic book, $F(1$, $238)=8.98, p<.003$, and gender, $F(1,238)=5.66, p<.02$, were significant. Results indicated that participants reading EVCB responded more aggressively than participants reading NVCB did and females responded more negatively than males. However, the Comic Book $\times$ Gender interaction effect was also significant $F(1,238)=4.61, p<.035$. Pair-wise comparisons indicated that females reading EVCB responded more aggressively than did females reading NVCB $(p<.001)$ and males reading EVCB $(p<.003)$ or NVCB $(p<.001)$. However, males reading EVCB did not differ from males reading NVCB. The follow-up univariate Trait Hostility $\times$ Gender interaction effect approached significance, $F(1,238)=3.56, p<.06$. Inspection of the means suggests a trend indicating that high hostile females provided the most negative responses. Both the follow-up univariate for trait hostility, $F(1$, $238)=6.16, p<.19$, and the Trait Hostility $\times$ Comic Book interaction effect, $F(1,238)=0.32, \mathrm{p}<.57$, were nonsignificant. Table 2 presents the estimated means and standard errors for the composite variables. 
TABLE 2: Estimated Means and Standard Errors of Overt and Relational Aggression as a Function of Comic Book, Gender, and Trait Hostility

\begin{tabular}{|c|c|c|c|c|}
\hline & \multicolumn{4}{|c|}{ Aggression Conflict Type } \\
\hline & \multicolumn{2}{|c|}{ Overt } & \multicolumn{2}{|c|}{ Relational } \\
\hline & M & SE & M & SE \\
\hline \multicolumn{5}{|l|}{ Comic book } \\
\hline Nonviolent (NVCB) & 11.4 & 0.57 & 8.2 & 0.41 \\
\hline Extremely violent (EVCB) & 15.2 & 0.57 & 10.1 & 0.41 \\
\hline \multicolumn{5}{|l|}{ Gender } \\
\hline Female & 11.5 & 0.43 & 9.8 & 0.31 \\
\hline Male & 15.1 & 0.62 & 8.5 & 0.45 \\
\hline \multicolumn{5}{|l|}{ Trait hostility $(\mathrm{TH})$} \\
\hline Low & 12.4 & 0.52 & 8.8 & 0.38 \\
\hline High & 14.2 & 0.51 & 9.5 & 0.37 \\
\hline \multicolumn{5}{|l|}{ Comic Book $\times$ Gender } \\
\hline NVCB female & 9.3 & 0.67 & 8.2 & 0.46 \\
\hline NVCB male & 13.5 & 0.85 & 8.1 & 0.62 \\
\hline EVCB female & 13.7 & 0.70 & 11.4 & 0.51 \\
\hline EVCB male & 16.7 & 0.92 & 8.8 & 0.67 \\
\hline \multicolumn{5}{|l|}{ Comic Book $\times \mathrm{TH}$} \\
\hline NVCB low TH & 9.9 & 0.76 & 7.7 & 0.55 \\
\hline NVCB high TH & 12.9 & 0.77 & 8.7 & 0.56 \\
\hline EVCB low TH & 14.8 & 0.79 & 9.9 & 0.57 \\
\hline EVCB high TH & 15.6 & 0.55 & 10.3 & 0.55 \\
\hline \multicolumn{5}{|l|}{$\mathrm{TH} \times$ Gender } \\
\hline Low TH female & 10.5 & 0.59 & 8.9 & 0.43 \\
\hline High TH female & 12.5 & 0.61 & 10.7 & 0.44 \\
\hline Low TH male & 14.3 & 0.89 & 8.6 & 0.64 \\
\hline High TH male & 16.0 & 0.84 & 8.3 & 0.61 \\
\hline \multicolumn{5}{|l|}{ Comic Book $\times \mathrm{TH} \times$ Gender } \\
\hline NVCB low TH female & 7.4 & 0.89 & 7.4 & 0.65 \\
\hline NVCB high TH female & 11.1 & 0.93 & 9.1 & 0.67 \\
\hline NVCB low TH male & 12.6 & 1.2 & 8.0 & 0.88 \\
\hline NVCB high TH male & 14.6 & 1.1 & 8.3 & 0.85 \\
\hline EVCB low TH female & 13.6 & 0.91 & 10.5 & 0.66 \\
\hline EVCB high TH female & 13.7 & 0.91 & 12.3 & 0.66 \\
\hline EVCB low TH male & 16.1 & 1.3 & 9.3 & 0.95 \\
\hline EVCB high TH male & 17.4 & 1.2 & 8.4 & 0.89 \\
\hline
\end{tabular}

\section{DISCUSSION}

Although males and females perceive the same level of violence in both EVCB and NVCB, males liked and showed more interest in EVCB whereas 
females liked and showed more interest in NVCB. These findings are consistent with previous research. For instance, Collins-Standley, Gan, Yu, and Zillman (1996) demonstrated that 2- to 4-year-old boys preferred fairy tales replete with violence whereas girls of the same age preferred romantic fairy tales. Similarly, Valkenburg and Janssen (1999) established that firstthrough fourth-grade Dutch and American boys, more so than same-age girls, preferred television shows with violence. Thus, cutting across age, culture, and presentation media (e.g., television, books, and comic books), males, more so than females, generally prefer media laden with violence. The question of why males and females perceive similar levels of aggression but prefer different levels of aggression remains an intriguing one. Research has shown that preferences are not readily predictable from cognitive judgments (Zajonc, 1998). Thus, much more research is needed to determine the relationship between the objective properties of stimuli perception and the objective features of the stimuli that account for our preferences (Zajonc, 1998). However, social cognitive factors such as appraisals and interpretations influence the likelihood of an individual's acting aggressively (Anderson \& Bushman, 2002). Perhaps perceiving extremely violent material as being humorous, likeable, and interesting alters the impact of those acts. Research on adolescent's television watching and aggressive tendencies supports this contention. Walker and Morley (1991) found that the biggest predictor of adolescent aggressive intent was liking television violence, rather than simply viewing television violence.

Similar to previous research (e.g., Bushman \& Geen, 1990), at the multivariate level, trait hostility was significantly related to the aggressive responding of participants. These findings support Bushman's (1998) contention that an individual with a chronically aggressive network (e.g., a person high in trait hostility) will typically demonstrate aggressive biases in SIP. However, univariate follow-up tests indicated that individuals high in trait hostility gave the most aggressive responses to scenarios involving overt aggression but not for scenarios involving relational aggression. This finding contradicts Kirsh and Olczak's (2002) earlier work, which found that trait hostility was significantly correlated with relational intent. However, the current assessment used only three relational provocation scenarios, whereas the Kirsh and Olczak study used six relational provocation scenarios. Although the trend toward significance is similar to that of earlier studies, there may not have been enough variability in the current data to elicit significant differences. However, the possibility also exists that the inconsistent findings between studies reflects problems with the reliability and/or validity of the newly adapted measure as an assessment tool of biased SIP. As such, the data should be interpreted with caution and require replication. Problems in vari- 
ability may also explain why some of the hypotheses involving the interactions between trait hostility, gender, and comic book for both overtly aggressive and relationally aggressive conflict types trended in the predicted directions (i.e., high hostile males reading EVCB reported the greatest number of negative responses for overtly aggressive conflicts, and high hostile females reading EVCB provided the most negative responses for relationally aggressive conflicts) but were not statistically significant.

The results of the present study are consistent with earlier work finding relationships between exposure to violent media and aggressive biases in SIP (Anderson \& Dill, 2000, Bushman \& Geen, 1990; Lynch et al., 2001). As predicted, exposure to EVCB influenced the perception of both overtly and relationally ambiguous provocation situations. Participants showed evidence of aggressive biases in SIP in that they manifested more aggressive responses after reading EVCB, as compared to NVCB. Regardless of whether the dependent variable involved overt or relational aggression, EVCB depicting only overt aggression influenced both types of responding. These data support Bushman's (1998) contention that an active aggressive network influences SIP, even if the source of the activation is different from the type of aggressive responding displayed. In addition, the results of the current study suggest that EVCB influence SIP in a manner similar to that of other forms of violent media, such as video games (Anderson \& Dill, 2000), movies, and television (Geen, 1998).

Anderson and Bushman (2002) have proposed a general aggression model (GAM) to account for the effects of violent media on aggressive behavior. According to the GAM, personological variables (e.g., trait hostility, attitudes toward violence) and situational variables (e.g., exposure to real-world or media violence) interact to influence an individual's present internal state. Within an individual's internal state, cognitions (e.g., aggressive scripts, hostile thoughts), affects (e.g., hostile feelings) and arousals (e.g., heart rate, blood pressure) influence one another. For example, hostile thoughts (a cognition) can increase hostile feelings (an affect). Subsequently, cognitions, affects, and arousal interact to influence an individual's interpretation of an aggressive act (e.g., harm-doer has hostile or benign intent). Once an interpretation has been made (i.e., harm-doer had benign or malevolent intent), decision-making processes (e.g., aggress, ignore) occur.

When applied to exposure to comic book violence, the GAM model suggests that violent comic books may influence aggressive behavior through both short-term and long-term effects. In the short term, violent video games function as a situational variable, resulting in an increase in aggressive cognitions, affects, and arousal. Bushman and Anderson (2001) have recently produced a meta-analytic review that provides empirical support for 
the contention that violent video games lead to aggressive behavior, aggressive cognitions, hostile affects, and increased physiological arousal. Our data suggest that similar effects may be present after reading violent comic books, at least for the cognitive component of the model. Participants in our study demonstrated hostile cognitions after a short-term exposure to violent comic books.

In the long-term, violent media are hypothesized to influence aggressive behavior by promoting aggressive beliefs and attitudes and creating aggressive schema, aggressive behavioral scripts, and aggressive expectations, as well as desensitizing individuals to aggression. In turn, these factors bias an individual's personality toward aggression. At this time, there are no longitudinal data to support the long-term effects of exposure to video game violence and comic books. However, given the similarities between different forms of media violence and the fact that long-term exposure to television violence is significantly associated with increased aggressive behavior (Strasburger, 1995), the long-term impact of exposure to violent comic books may also conform to GAM predictions.

As predicted, significant gender differences in the processing of overt and relational ambiguous provocation situations were evident. For the ambiguous stories involving overt aggression, the responses of males were significantly more aggressive than the responses of females were. In contrast, for the ambiguous stories involving relational aggression, the responses of females were significantly more aggressive than the responses of males were. These findings are consistent with research on aggressive behavior that indicates that whereas overt aggression is characteristic of males, relational aggression appears to be more characteristic of females (Crick \& Grotpeter, 1995). Furthermore, these current results suggest that the aggressive networks of both males and females can be activated by violent media. However, our findings suggest that the activated aggressive networks of males may function differently than the activated aggressive networks of females. The aggressive networks of females appear to be more attuned to relational aggression, whereas the aggressive networks of males appear to be more attuned to instrumental aggression. Given that participants responded to both overt and relational scenarios at the same time, why is it that gender was related to the amount of negative responding?

Huesmann (1988) contended that in response to experiences with aggressive behavior, including the observation of aggressive acts performed by others, individuals develop aggressive scripts. These scripts contain information regarding the participants and events surrounding the aggressive act, such as the nature of the provocation and subsequent response. A review of the literature suggests that males and females may have different aggressive scripts, 
with the aggressive scripts of males focusing on overt aggression, and the aggressive scripts of females focusing on relational aggression (Geen, 1998). Similarly, the data from the present study suggest that short-term exposure to EVCB may trigger already developed aggressive scripts: overt scripts for males and relational scripts for females.

As a caveat, there are several methodological limitations to the current study. First, the present results were found using a relatively small sample of comic books (i.e., six to seven comic books per condition), thus potentially limiting the generalizability of the findings (Wells \& Windschitl, 1999). Second, the possibility exists that the methodological procedure of having participants "think like a 10-year-old" led to SIP that would not have occurred if the participants had been asked to provide their own responses. However, given the dependent measure's projective nature, a participant's interpretations of ambiguous stimuli, regardless if done for the self or for how another might think, should primarily reflect the participant's current state of mind with regard to hostile/nonhostile perceptions. Third, although we attempted to reduce the demand characteristics of the study through deception, it is possible that some participants figured out the intent of the study and responded accordingly. Fourth, there were very few participants in the current study who frequently read comic books. Thus, additional research is necessary to determine whether frequency of exposure to this form of violent media influences SIP. Furthermore, additional research is necessary to determine how long after reading EVCB the negative perception of social situations lasts.

In conclusion, the processing of overt and relationally aggressive ambiguous provocation situations appears to be affected by gender; personalitybased variables, such trait hostility; and environmental factors, such as EVCB. In addition, the effect of violent media on SIP appears to be related to the type of aggressive conflict under assessment, with differential impact occurring for males and females. These findings underscore current theories of aggression (e.g., Anderson \& Bushman, 2002) that emphasize the complex role that both situational and individual difference variables play in determining aggressive behavior.

APPENDIX

\section{Instrumental Stories}

1. Pretend that you're walking outside and you're wearing your new tennis shoes. You really like your new shoes and it's the first day that you have worn them. Suddenly, you are bumped from behind by another kid. You stumble and fall into a puddle and your new shoes get muddy. 
2. Pretend that you have just finished drawing a big picture. You have worked on it a long time, and you really like it. Another kid comes over to look at your picture. He's holding a jar of paint in his hand. You turn away for a minute and when you look back the other kid has spilled paint on your drawing. Rats, you worked on the picture for a long time and now it's just a big mess.

3. Pretend that you are standing on the playground playing catch with a bunch of kids. You throw the ball to another kid and the kid catches it. You turn around, and the next thing you realize is that the kid has thrown the ball and hit you in the middle of your back. The ball hit you hard, and it hurts a lot.

\section{Relational Scenarios}

1. Imagine that you are looking for your friend on the playground. You can't wait to find your friend because you have an important secret to share. By the time you find your friend, your friend is already playing with someone else-a kid you don't like very much.

2. Imagine that you are at lunch one day and looking for a place to sit. You see some kids you know at a table across the room. The kids are laughing and talking to each other, and they look like they are having a good time. You walk over to their table. As soon as you sit down, the kids stop talking and no one says anything to you.

3. Imagine that you are looking in the mirror in the bathroom one day after class. While you are in there, two other kids from your class come in and start talking to each other. You hear one of the kids invite the other one to a birthday party. The kid says that there are going to be a lot of people at the party. You have not been invited to this party.

\section{REFERENCES}

Anderson, C. A. (1997). Effects of violent movies and trait hostility on hostile feelings and aggressive thoughts. Aggressive Behavior, 23, 161-178.

Anderson, C. A., \& Bushman, B. J. (2002). Human aggression. Annual Review of Psychology, $53,27-51$.

Anderson, C. A., \& Dill, K. E. (2000). Video games and aggressive thoughts, feelings, and behavior in the laboratory and in life. Journal of Personality and Social Psychology, 78, 772 790.

Bartholow, B. D., \& Anderson, C. A. (in press). Examining the effects of violent video games on aggressive behavior: Potential sex differences. Journal of Experimental Social Psychology.

Bushman, B. J. (1998). Priming effects of media violence on the accessibility of aggressive constructs in memory. Personality and Social Psychology Bulletin, 24, 537-545.

Bushman, B. J., \& Anderson, C. A. (2001). Media violence and the American public: Scientific facts versus misinformation. American Psychologist, 56, 477-489.

Bushman, B. J., \& Geen, R. G. (1990). Role of cognitive-emotional mediators and individual differences in the effects of media violence on aggression. Journal of Personality and Social Psychology, 58(1), 156-163.

Buss, A. H., \& Durkee, A. (1957). An inventory for assessing different kinds of hostility. Journal of Consulting Psychology, 21, 343-349. 
Collins-Standley, T., Gan, S., Yu, H. J., \& Zillman, D. (1996). Choice of romantic, violent, and scary fairy-tale books by preschool boys and girls. Child Study Journal, 26, 279-302.

Crick, N. R. (1995). Relational aggression: The role of intent attributions, feelings of distress, and provocation type. Development and Psychopathology, 7, 313-322.

Crick, N. R., \& Grotpeter, J. K. (1995). Relational aggression, gender, and social-psychological adjustment. Child Development, 66, 710-722.

Dill, K. E., Anderson, C. A., Anderson, K. B., \& Deuser, W. E. (1997). Effects of aggressive personality on social expectations and social perceptions. Journal of Research in Personality, 31, 272-292.

Dodge, K. A. (1980). Social cognition and children's aggressive behavior. Child Development, $51,162-170$.

Dodge, K. A. (1986). A social information processing model of social competence in children. In M. Perlmutter (Ed.), Minnesota symposium on child psychology (pp. 77-125). Hillsdale, NJ: Lawrence Erlbaum.

Dodge, K. A., \& Crick, N. R. (1990). Social information-processing bases of aggressive behavior in children. Personality \& Social Psychology Bulletin, 16, 8-22.

Dodge, K. A., Pettit, G. S., McClaskey, C. L., \& Brown, M. M. (1986). Social competence in children. Monographs of the Society for Research in Child Development, 51(2, Serial No. 213).

Dubow, E. F., \& Miller, L. S. (1996). Television violence viewing and aggressive behavior. In T. M. MacBeth (Ed.), Tuning in to young viewers: Social science perspectives on television (pp. 117-148). London: Sage.

Epps, J., \& Kendall, P. C. (1995). Hostile attributional bias in adults. Cognitive Therapy and Research, 19, 159-178.

Funk, J. B. (1993). Reevaluating the impact of violent video games. Clinical Pediatrics, 32, 8690.

Geen, R. G. (1998). Aggression and antisocial behavior. In T. Gilbert, S. T. Fiske, \& G. Lindzey (Eds.), The handbook of social psychology (4th ed., vol. 2., pp. 317-356). Boston: McGrawHill.

Huesmann, L. R. (1988). An information processing model for the development of aggression. Aggressive Behavior, 14, 13-24.

Kirsh, S. J. (1998). Seeing the world through "Mortal Kombat" colored glasses: Violent video games and the development of a short-term hostile attribution bias. Childhood, 5, 177-184.

Kirsh, S. J., \& Olczak, P. V. (2000). Violent comic books and perceptions of ambiguous provocation situations. Media Psychology, 2, 47-62.

Kirsh, S. J., \& Olczak, P. V. (2002). Violent comic books and judgments of relational aggression. Violence and Victims, 17, 373-380.

Knott, P. D. (1970). A further methodological study of the measurement of interpersonal aggression. Psychological Reports, 26, 807-809.

Lynch, P. L., Gentile, D. A., Olson, A. A., \& van Brederode, T. M. (2001, April). The effects of violent video game hostile attributional bias on adolescent aggressive attitudes and behavior. Poster session presented at the biennial conference of the Society for Research in Child Development.

McCloud, S. (1993). Understanding comics. Northampton, MA: Kitchen Sink.

Parke, R. D., \& Slaby, R. G. (1983). The development of aggression. In P. H. Mussen and M. Hetherington (Eds.), Handbook of child psychology: Vol. 4. Socialization, personality, and social development (4th ed., pp. 547-642). New York: John Wiley.

Petzel, T. P., \& Michaels, E. J. (1973). Perception of violence as a function of levels of hostility. Journal of Consulting and Clinical Psychology, 41, 35-36. 
Potenza, M., Verhoeff, P., \& Weiss, E. (1996). Comic books and development. Journal of the American, Academy of Child and Adolescent Psychiatry, 35, 1573-1574.

Strasburger, V. C. (1995). Adolescents and the media: Medical and psychological impact. London: Sage.

Valkenburg, P. M., \& Janssen, S. C. (1999). What do children value in entertainment programs? A cross-cultural investigation. Journal of Communication, 49(2), 3-21.

Walker, K. B., \& Morley, D. D. (1991). Attitudes and parental factors as intervening variables in the television violence-aggression relation. Communication Research Reports, 8, 41-47.

Walsh, D. A. (1999). 1999 video and computer game report card. Retrieved from http:// www.mediafamily.org/research/vgrc/1999-1.shtml

Wells, G. L., \& Windschitl, P. D. (1999). Stimulus sampling and social psychological experimentation. Personality and Social Psychology Bulletin, 25, 1115-1125.

Zajonc, R. B. (1998). Emotions. In D. T. Gilbert, S. T. Fiske, \& G. Lindsey (Eds.), The handbook of social psychology, (4th ed., vol. 1, pp. 591-632). Boston: McGraw-Hill.

Steven J. Kirsh is an associate professor in the Department of Psychology at the State University of New York, Geneseo. His research focuses on the influence of violent media on social information processing.

Paul V. Olczak is a professor and chairperson in the Department of Psychology at the State University of New York, Geneseo. He has received two awards for his research and has coauthored one book and published more than 40 book chapters and articles on a variety of topics, including psychology and the law, conflict resolution, behavior modification, interpersonal psychiatry, and individual differences. 